\title{
Through of Beach Space Design for Person with Disabilities Based on Universal Design Principles
}

\author{
Rachmita Maun Harahap ${ }^{1,}$ Imam Santosa², Deddy Wahjudi², Widjaja Martokusumo² \\ ${ }^{\prime}$ Doctoral program on Science of Art and Design, Bandung Institute of Technology \\ ${ }^{2}$ Senior Lecturer of Bandung Institute of Technology
}

\begin{abstract}
Most of existing public facilities in Indonesia, beach spaces become one of less accommodating places for people with disabilities. Researchers believe that the beach is a natural wealth of country that is entitled to be enjoyed by every layer of Indonesian society. Therefore, the beach space design becomes a place that needs to be developed in functional aspects in meeting the needs of people with disabilities. Researchers show that designers and architects are actors who have a role in creating human living space. In carrying out the role, must be aware that background and needs of human beings are very diverse. Researcher is also a hearing disabilities and "One Space" jury team begins an assessment for importance of universal design on beach space. The paper presented discussed the design of a beach space themed "One Space" with universal design principle approach as substitute for evaluation of 6 finalists of the best work design.
\end{abstract}

Keywords: beach space, one space, person with disabilities, universal design

\section{Research Background}

An interior designer has obligation to produce a work that isn't only concerned with aesthetics but to bring users together. Through the design of beach space, awareness build of young designer and architect of archipelago in a series of contest events and exhibition of works result themed "One Space". One space is interior design competition to increase social sensitivity in growing awareness of comfort for persons with disabilities through design works for students of interior design and architecture at Indonesia.

Beach space facilities with universal design approach haven't become commonly application in Indonesia. Design of beach spaces have but not yet been application to universal design taking into consideration the needs of parties with physical limitations, specific age ranges, as well as gender differences in balanced manner.

\footnotetext{
* Corresponding author: Rachmita M. Harahap mitha_hrp@ymail.com

Published online at http://IJDS.ub.ac.id/2019- 1

Copyright $@$ 2019PSLD UB Publishing. All Rights Reserved
}

The paradigm thinks that applied universal design is expensive application has resulted in insufficient effort for application and development of universal design. Whereas with applied of universal design, indirectly will facilitate users all of facility without exception. Thus user productivity can be increased to produce a fruit of investment if one day experiencingof age degradation and physical.

In addition of regulatory developments of Ministerial Decree No 14 of 2017 [1] on the Ease of Building Requirements and public awareness of facilities that meet of universal design principles for disability users are less attention in the world of design practitioners. Although in standard rules of construction applications have included of applied of facilities design can universally accessible, concepts and universal design methods aren't general taught in design education environment. Manager programs of interior design study are often lacking in awareness, sensitivity, information and skills to teach for caollege students about issues of personw with disabilities (PwDs), minimum standards and art conditions in accessibility design [2]

Competition contest and exhibition of design work of beach space that themed one 
space which was initiated by organizers of student Association of interior design on Pelita Harapan University and invited of jury team including researchers as juries representing persons with disabilities who understand of universal design. The main purpose of competition is to awareness raise and social awareness, especially for students of young designers to disability through design work that will ultimately be able to answer the needs of PwDs and criticisms submit that are accompanied by provision of solutions to design of upcoming buildings with a design that more consider the existence persons with disabilities through design work. The next objective is to generate a variety of beach space design references by meeting universal design principles or accessible.

The competition contest object of beach space design is chosen on grounds that coast is Indonesia have the second longest beach line in world of around $54,716 \mathrm{~km}$ and beach entire this is entitled to be enjoyed by levels all of Indonesian society [3].

But until now the beach is still less accommodate for people with disabilities, so that people with disabilities less get a memorable of experience beach space. Other than aesthetic aspect, functional and economic, another important criterion is ability of interior designers to compromise the specific needs of disabilities users with the needs of other groups aren't disabilities (normal).

The competition contest of design work "One Space" 2017 it is open to public or students, start of registration (June 12, 2017) and collection of June 9, 2017. Closed judgment results (June 16, 2017) and the results of the judging open the winner of the design work of the 6 best finalists 7 July 2017) from 25 participants. Results of contest were exhibited by 25 participants of design work at Galeri Salihara, Pasar Minggu - South Jakarta (6 - 9 July 2017) [3].

After process all effort to socialize and awareness raise through a competition, an evaluation of assessment criteria that is : 1) creativity and innovation in offering an interesting space for disabilities and 2) the underlying concept of design, where the concept must have continuity and answer of problems found on beach space and offered solutions.

The following is a study of design a beach space with a universal design approach and evaluation of 6 best finalists of design work on contest it. Results expect to be used as reference to design something space design with adequate universal design standards so that everyone including persons with disabilities can enjoy beauty of coast of Indonesia with maximum, in accordance with the necessary needs.

\section{Theoretical Review}

\subsection{Definition of Universal Design}

There is some understanding of Universal Design that is principle of same with editorial details of different from sources some, among others :

- Universal design means simply designing all products, building and exterior spaces to be usable by all people to the greatest extent possible [4].

- Universal design can be defined as the design of products and environments to be usable to the greatest extent possible by people of all ages and abilities [5].

- Universal design is an approach to design that incorporates products as well as building features and elements which, to the greatest extent possible, can be used by everyone [6].

Universal design that will be discussed in article is more understood as approach in design. Universal design is a design approach to facilities produce and products for users all without physical limitations, age ranges, and also gender. With a design approach this, facility and product will experience a 'compromise' so that everyone as user can be accommodated for their needs in activiy, without exclusive of part people.

Good design and be equipped with attention to human factor issues of users can be key to solving problems in universal design. Human factor issue relates to physical condition of humans in use of design products, and is standard of principles in universal design approach. Principles in universal design according to Story (1998: 34-35) are as follows : 1) Equitable Use is design is useful and marketable to people with diverse abilities; 2) Flexibility in Use is design accommodates a wide range of individual preferences and abilities; 3) Simple and Intuitive Use is use of the design is easy to understand, regardless of 
the user's experience, knowledge, language skills, or current concentration level; 4) Perceptible Information is design communicates necessary information effectively to the user, regardless of ambient conditions or the user's sensory abilities; 5) Tolerance for Error is design minimizes hazards and the adverse consequences of accidental or unintended actions; 6) Low Physical Effort is design can be used efficiently and comfortably and with a minimum of fatigue: and 7) Size and Space for Approach and Use. Appropriate size and space is provided for approach, reach, manipulation, and use regardless of user's body size, posture, or mobility.

7 principle of applies generally to areas all of interior design and architectural, especially in form of beach space facilities. In particular, 7 principles can also be applied to beach space facilities for disabilitiy visitors.

\subsection{Understanding Beach Space Design}

The design works of "One Space" that themed beach space received by committee are very diverse in concept. Diversity of concept of work departs from diverse perceptions and understanding of interior designers against of universal design principles approach. Each strives to application of understanding of universal design in accessible design of beach space, with a touch of concept that is supposed to embody of applied design. The concepts emerging in design work have different emphases, according to background of knowledge of design, philosophy, technical, and global environmental issues.

The design works of beach space is dominantly of composed of circular, curved, geometric, parallelogram, organic and etc. Each composition represents the concept and style applied by the designer. Although there are alternative experiments that dare to come up with creative forms outside of general form, but not ignores of main function the design object to activities accommodate of users all as goal.

Conditions the design of beach space may be real or existing locations (eg beaches of Tanjung Tinggi in Belitung, Pandawa beaches in Bali, etc.) or fictitious beach where participants can create of situatuion and conditions in accordance with problems to be solved through design solutions. Spatial interventions can be indoor, outdoor, or a combination of both. Facilities can be specific to persons with disabilities (eg acoustic installation for hearing disabilities), and friendly of persons with disabilities but can also be used by general public. Here are documentation part from design work that goes to competition committee [7]:
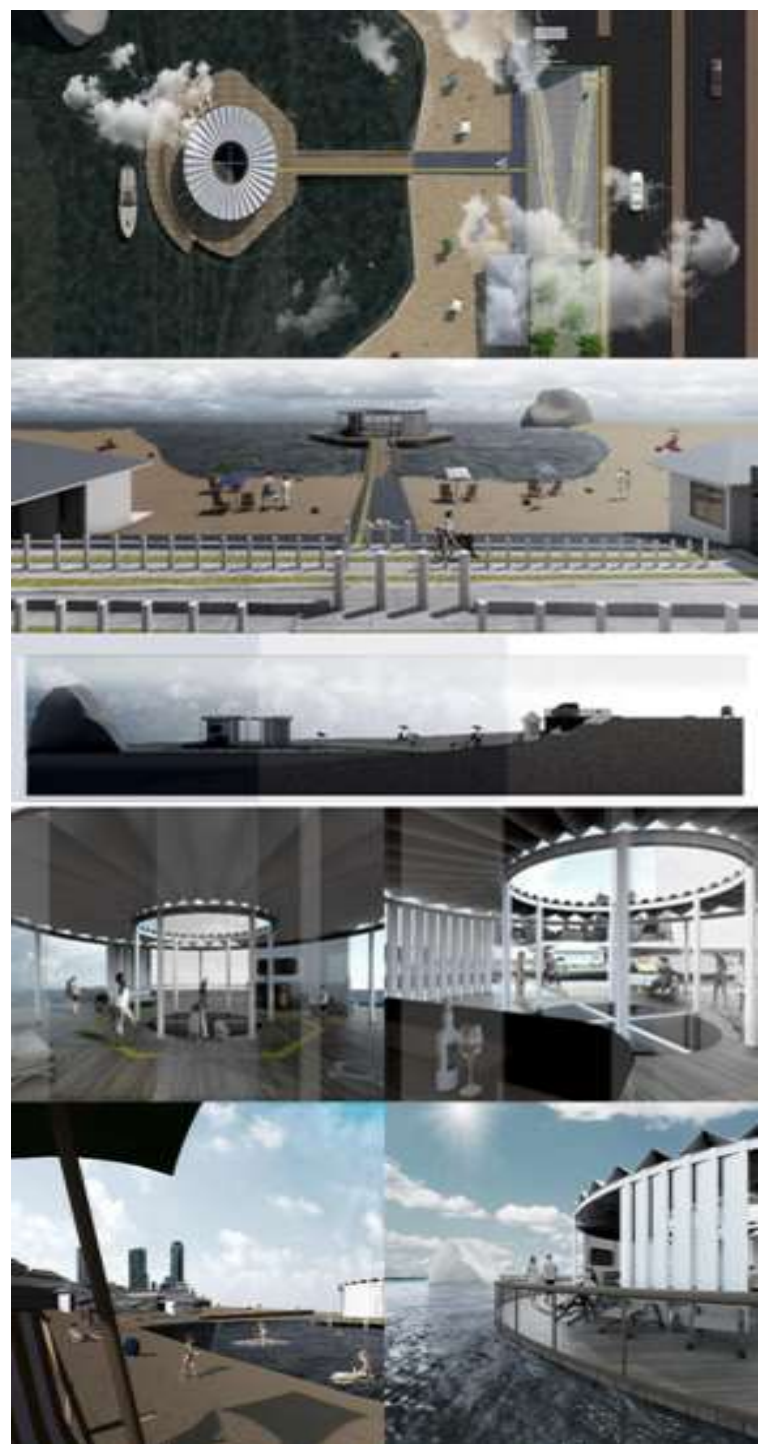

Figure 1. Design work "Parallel Beach" Source : HMDI-UPH, 2017

Rachmita M. Harahap, et al. Through of Beach Space Design for Person with Disabilities Based on Universal Design Principles. Indonesian Journal of Disability Studies (IJDS).2019: Vol. 6(1): PP 7-13. 
IJDS 2019; Vol.6 No. 1, Mei 2019, pp. 7-13

ISSN: $2355-2158$

DOI: dx.doi.org/10.21776/ub.ijds.2019.006.01.1

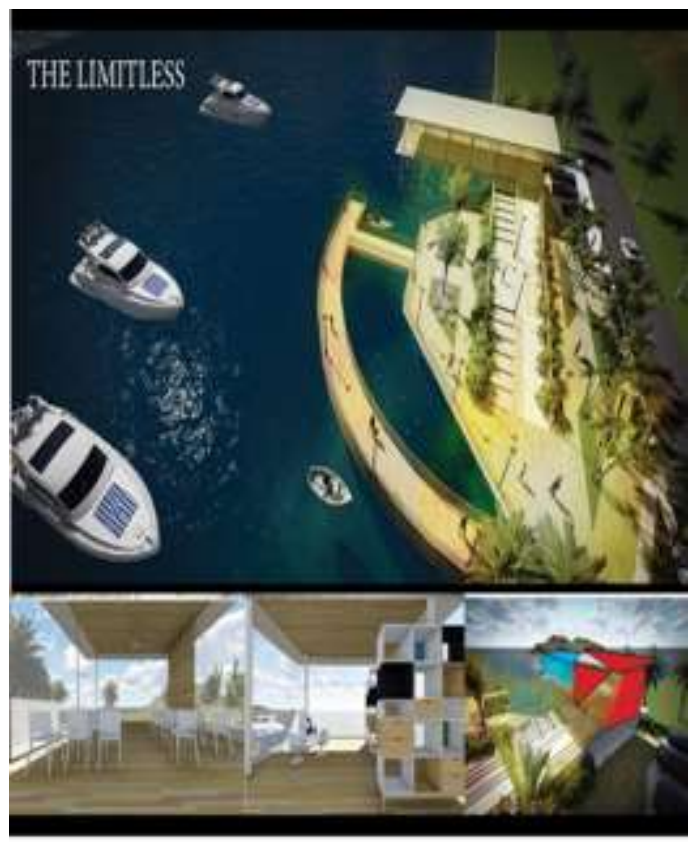

\section{0}
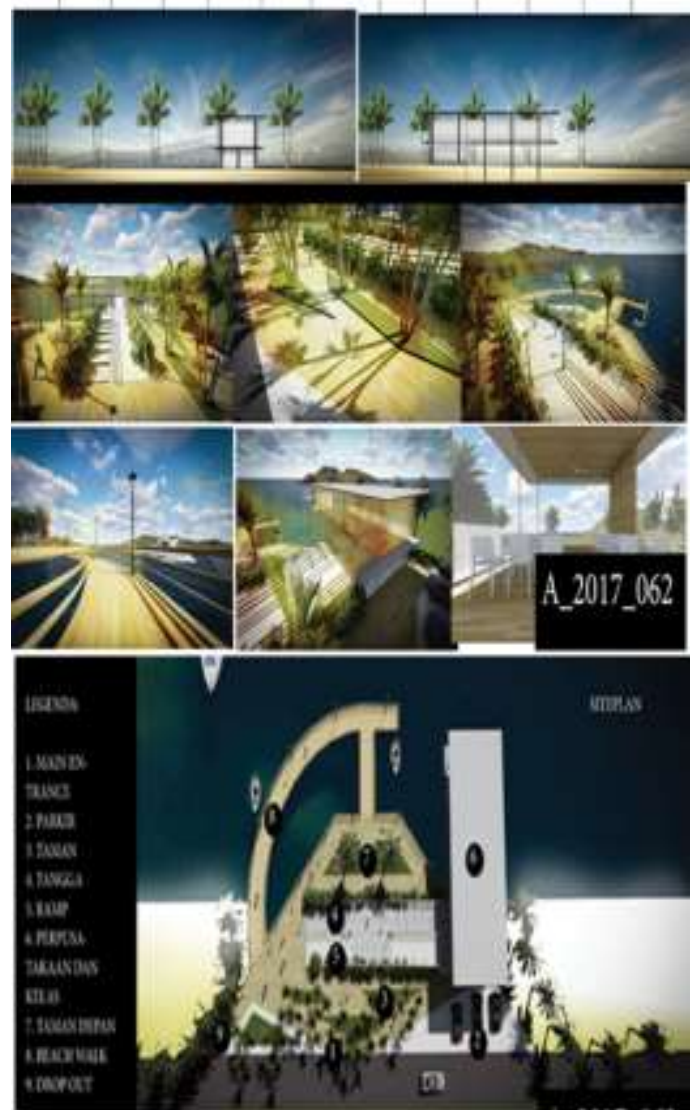

Figure 2. Design work "The Limitless" Source : HMDI-UPH, 2017

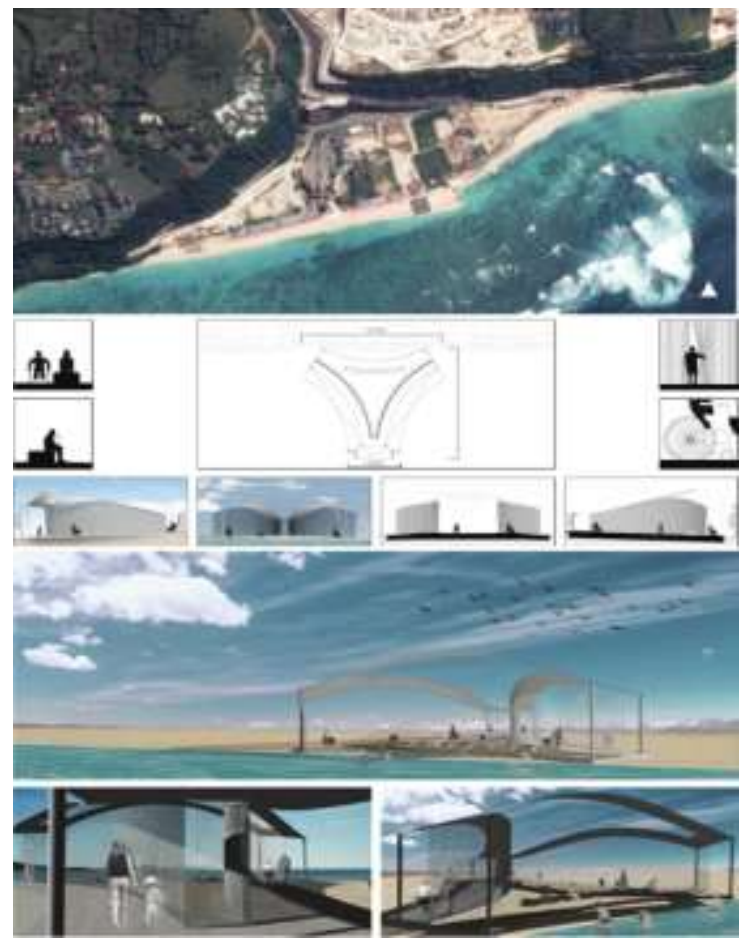

Figure 3. Design work "Journey to Water" Source : HMDI-UPH, 2017

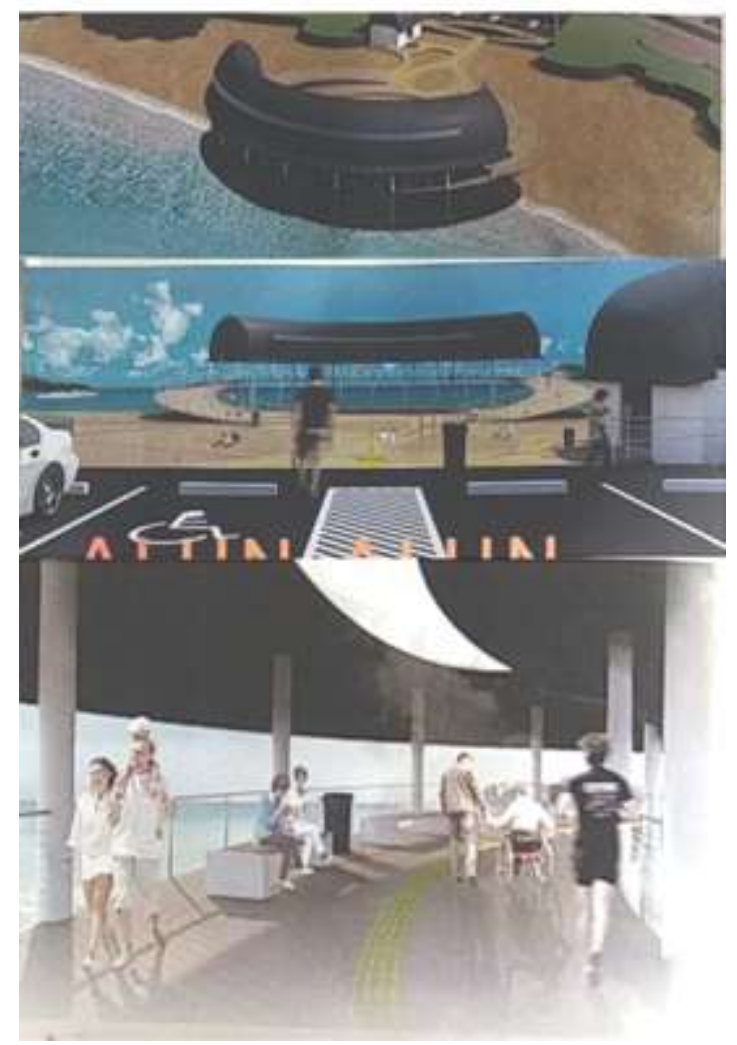

Figure 4. Design work "Senggigi Square" Source : HMDI-UPH, 2017

Cite this as:

Rachmita M. Harahap, et al. Through of Beach Space Design for Person with Disabilities Based on Universal Design Principles. Indonesian Journal of Disability Studies (IJDS).2019: Vol. 6(1): PP 7-13. 


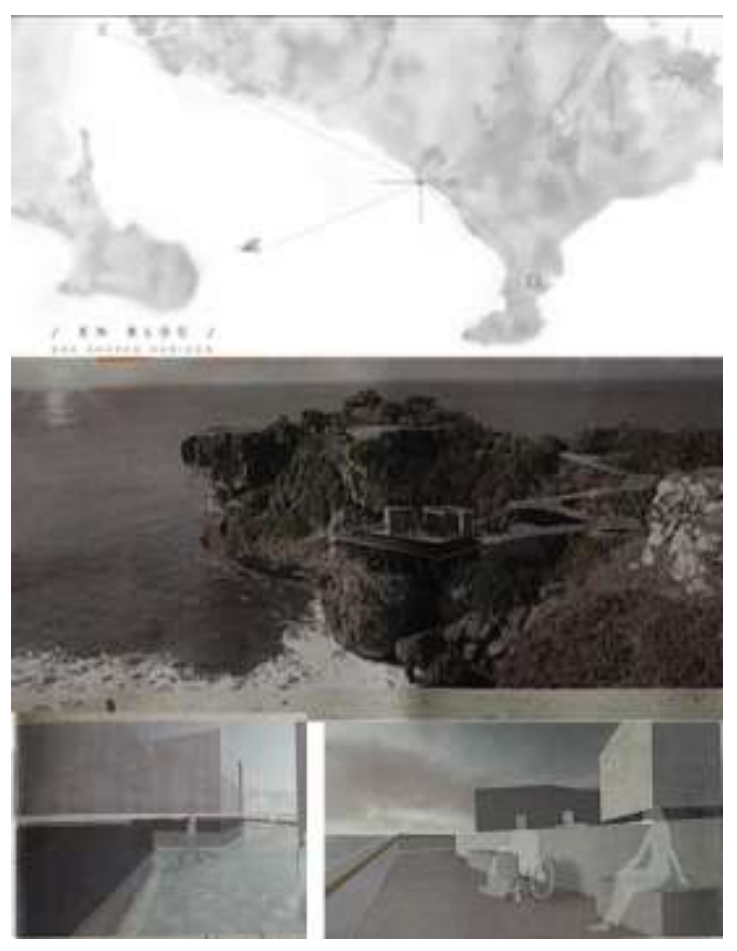

Figure 5. Design work "En Bloc" Source : HMDI-UPH, 2017

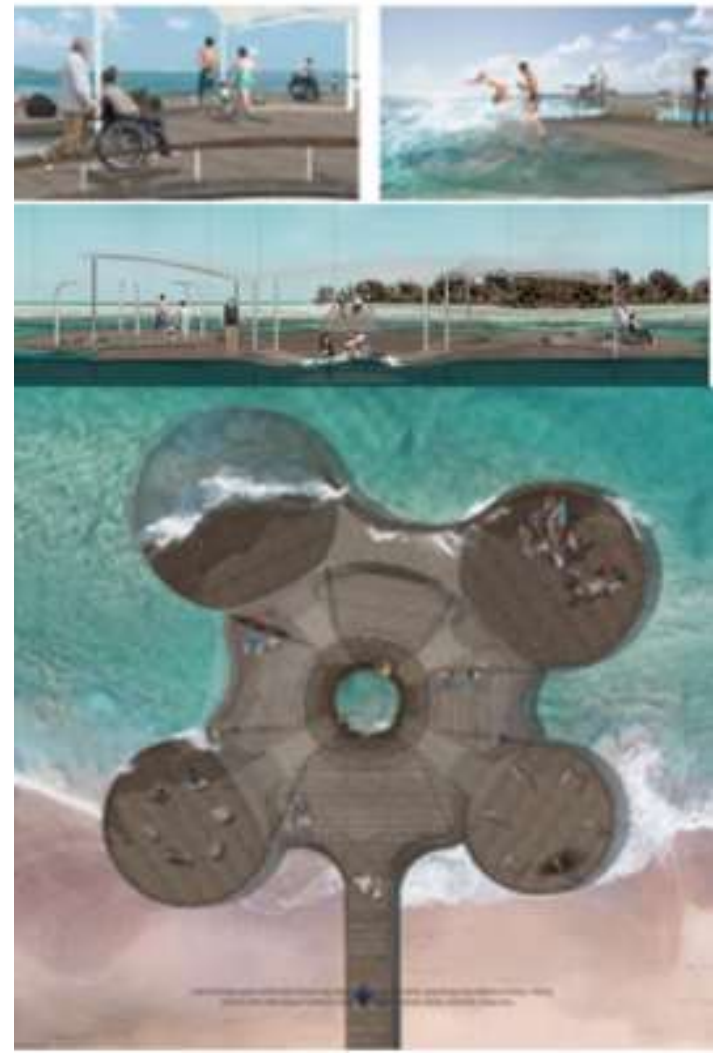

Figure 6. Design work "Build Opportunity, Build Beach"

Source : HMDI-UPH, 2017
Description of work design of beach space above mentioned below discuss each title of design theme. Design of beach space was making using international standard reference (size and installation) which is summary in Leslie C. Young's book Curbless Shower: An Instalation Guide [8].

The design concept of beach space that appliedd some carefully designed concepts are designed to maximize of space experience that permeates the limitations and accordance with human needs, as follows :

a. Physical disabilities (wheelchair users, stick crew)

A public space design, example located in Arizona, USA's providing of universal facility for garden lovers who have their own daily agenda of passing, relaxing, and talking. The placement of ramp in public space not anymore a strange thing because ramp is the best solution that successfully of replaces the ladder function for disabilities have limitations to move freely.

The problem will activity difficulty of effective due because to physical limitations, which directly impede one's traveling access, becomes faded with presence of ramp lines.

Besides of function from design elements applied, public garden have an identity as expressioN space, which prioritizes of aesthetics where things can attract the attention of good people around for a stopover.

Ramps designed on maximally where combine of contexts and greenery with extreme weather in Arizona make an experience of person's travel more memorable. The veiled of calculation are high in every placement of element of design composition, if done correctly it can break through of physical and mental restrictions of users so can to connect with community.

\section{b. Blind Disabilities}

The Low vison and Blind Disability Center specially designed by Mauricio Rocha brings the totality of comfort to blind community of daily living. The relation between space and structure is processed with contrast full from texture form, size, weight, and type of material chosen to increase work power of other senses to function more actively in translating the surrounding conditions. 
As strains of sound the air is designed to direct the goal, wall texture that forms a building motif that distinguishes the horizontal motif and vertical to become information in signifying each building and function, and strongly fragrant plants are planted in an open area in order to stimulate the orientation of the context in around this building.

\section{c. Hearing Disabilities}

Stelzhamerschule School-Linz, Austria designed specifically by Kirsch Architects brings the totality of comfort to the deaf to daily living. Inter-space and structural relationships are processed by prioritizing high visual orientation and encouraging the totality of other sensory experiences based on the Deaf Space philosophy (DeafSpace design).

DeafSpace principles aimed at expanding one's ability to respond to space with a range of 180-degree limitations. The transparency of every space can prevent a person's limitation in capturing activity in another room and maximize the space awareness to 360 degrees.

The use of road ramp as commonplace that prevents collisions between individuals, different repetition elements such as lines on walls and paths arranged to provide instinctive navigation, and the use of contrasting colors with skins such as blue or green to make it easier to read language movements cues from further distances greatly help the deaf to maximize other senses.

\section{Results and Discussion}

The evaluation of this "One Space" beach space design work will be emphasized on the application of universal design that has been generally pursued in every design. It is also necessary to discuss the various perceptions and participants' understanding of universal design approach adopted in an accessible design. Universal design, in this case is an approach that is attempted to be implemented through of media the competition of design work.

In general, design work of incoming from participants have adequately applied universal design and concept touch of unique and interesting. Almost all application of universal designs use of standard and dimensional of references same. Some aren't referring to universal design principles. The concept which

Cite this as:

Rachmita M. Harahap, et al. Through of Beach Space Design for Person with Disabilities Based on Universal Design Principles. Indonesian Journal of Disability Studies (IJDS).2019: Vol. 6(1): PP 7-13. has been transformed in design makes each design different, at least in visual form.

Emphasis on visual aesthetics, resulting in a quite harmonious visual composition. Emphasis on philosophy, producing a fairly thick thematic nuance. Emphasis on technology, resulting in a unified system and product form. Emphasis on environmental issues, resulting in applied systems that are not easily visualized without description.

It is expecting that organizers and jury team will be able to implement a system that can accommodate of activities for users all without exception and be able to indicate accessible of design work of beach space. While the competition headline is an accessible beach space design, participants can perceive it in various ways. If perceived as accessible for certain groups of users, and limited, it can lead to universal design.

The universal design may also apply to general use in public facilities, but may also apply privately to private facilities. Existing provided is a space that is on beach, canteen room or bar, toilet, lobby, and lounge or reading. This can be perceived as an accessible space for users all that is only used dominant by visitor. So there is also a design work that is a universal beach.

Differences of perceptions can be gaps that will affect both design work and assessment criteria. When of assessment criteria place emphasis on universal design principles, those that are considered to meet the criteria are designs that apply universal design in general. Beach space design is included in these criteria, because design results are also of high value in creativity and innovation in offering a space experience that is attractive to people with disabilities. Even the concept underlying the design, where the concept must have continuity and answer of problems found on beach and the solutions offered.

Regardless of design work, important to attention is also conformity of perception and level of understanding between design assignor and designer to produce of design work that suits the demands of the user's needs.

\section{Conclusion}

Implementation of beach space design with universal design approach to designers or architects, managers, practitioners, academics and design learner needs to be built maximally 
and effectively. In general, the Minister of PUPR regulation no. 14/PRT/M/2017 about convenience of requirement of building especially public facilities already contain things related to universal design application. Realization of real design objects has not been applied. Moreover in world of design academic, universal design approach has also not been an important part of content and exploration of teaching and learning.

One of implementation efforts initiated by researchers along with jury team in collaboration with Interior Design Student Association of Pelita Harapan University is holding a competition contest and exhibition of "One Space" beach space design work. Another goal is that results of contest design work are expected to create the same space and are used for joint, without distinction, but instead care for each other, especially for designers, this being one of most sensitive issues to consider and given the answer.

The design work of contest hasn't met the universal design principles because participants are still just beginning to understand the needs of people with disabilities. The organizers made the competition a part of universal design implementation effort, but competition's headline was formulated with accessibility. This makes of participants also confused in understanding and applying of approach. The gap of understanding, and also time to influence the design work of participants less than maximum.

However, evaluation of the design work of competition is also important for next implementation strategy. A complete and clear understanding of universal design is also becoming sharper, especially the similarities and differences between two. So that expected design results can be more leverage in accordance with demands required. Hope this implementation can effort of produce further results and real response, especially in field of teaching design.

\section{References}

Composition team of the Ministry of PUPR RI, 2017, Ease of building requirements No. 14 of 2017, Jakarta

Greer, N. R. Jan., 1987, The State of the Art of Design for Accessibility. Architecture, 58-61.

The organizer team of Pelita Harapan University Design University Student Association, 2017: One Room Competition 2018, through design, build awareness. Jakarta: Universitas Pelita Harapan

Mace, Ronald L., 1991, Accessible Environments: Toward Universal Design. New York: Van Nostrand Reinhold.

Story, Molly Follete, 1998, The Universal Design File: Designing for People of All Ages and Abilities. North Carolina State University.1998,page 34-35

Mace, Ronald. 2000. Universal Design: Housing for the Lifespan of All People. North Carolina State University.

The organizer team of Pelita Harapan University Design University Student Association, 2017: One Room Competition 2018, through design, build awareness. Jakarta: Universitas Pelita Harapan

Young, Leslie. C., 2003, Curbless Shower: An Instalation Guide. North Carolina State University.

The organizer team of Pelita Harapan University Design University Student Association, 2017: One Room Competition 2018, through design, build awareness. Jakarta: Universitas Pelita Harapan 